\title{
0419 PREDICTING SAFETY PERFORMANCE ASSOCIATED WITH HIGHWAY DESIGN DECISIONS: A CASE STUDY OF DHAKA - CHITTAGONG HIGHWAY
}

A S Huq* Correspondence: Accident Research Institute (ARI), Bangladesh University of Engineering and Technology (BUET), Dhaka-1000, Bangladesh

\subsection{6/ip.2010.029215.419}

Roads, highways and streets are fundamental in transportation system of Bangladesh. In Bangladesh the road safety situation is very severe with approximately 169 fatalities per 10000 motor vehicles which is highest in Asia. According to the police reported official statistics, there are at least 3764 fatalities and 3284 injuries in 4426 reported accidents in 2008 . The study has been intended to identify the causes behind the geometric problem of the selected segments of Dhaka-Chittagong highway. This research work comprises two segments on DhakaChittagong highway, that is, Segment A $(46+015.570 \mathrm{~km}$ post to $56+067.876 \mathrm{~km}$ post/Daudkandi to Comilla) and Segment B $(31+659.050 \mathrm{~km}$ post to $42+022.390 \mathrm{~km}$ post $/$ Kachpur to Daudkandi). Each segment includes $10 \mathrm{~km}$ length of the corridor. Analysis period covered in this research work is from 1998 to 2007 for Segment A and 1998 to 2003 for Segment B. In this study, attempt has been made to evaluate the performance of four modules (PRM, CPM, DCM and TAM) on the selected highway segments using 2006 version of Interactive Highway Safety Design Module (IHSDM). The research work investigates the causes of accidents, identities the factors involved in road accident causation geometric elements in particular, existing black spots and evaluation of safety measures. In Segment A, 84.2 crashes per year are predicted with $93 \%$ fatal and injury crashes and $7 \%$ property damage only crashes. On the other hand 73.5 crashes per year are predicted for Segment B with $96 \%$ fatal and injury crashes and $4 \%$ property damage only crashes. 